\title{
Stress and Coping Strategies among University Freshmen in Hong Kong: Validation of the Coping Strategy Indicator
}

\author{
Chi-Fai Lo',2,3 \\ ${ }^{1}$ Institute of Theoretical Physics and Department of Physics, The Chinese University of Hong Kong, Hong Kong, China \\ ${ }^{2}$ Department of Psychology, Sociology and Politics, Sheffield Hallam University, Sheffield, UK \\ ${ }^{3}$ Social and Human Sciences Section, SCOPE, City University of Hong Kong, Hong Kong, China \\ Email:edcflo@gmail.com
}

How to cite this paper: Lo, C.-F. (2017). Stress and Coping Strategies among University Freshmen in Hong Kong: Validation of the Coping Strategy Indicator. Psychology, 8, 1254-1266. https://doi.org/10.4236/psych.2017.88081

Received: May 16, 2017

Accepted: June 26, 2017

Published: June 29, 2017

Copyright $\odot 2017$ by author and Scientific Research Publishing Inc. This work is licensed under the Creative Commons Attribution International License (CC BY 4.0).

http://creativecommons.org/licenses/by/4.0/

\section{(c) () Open Access}

\begin{abstract}
This study has examined the validation of the Coping Strategy Indicator (CSI) with the 12-item General Health Questionnaire (GHQ-12) as a criterion for a sample of Chinese university students in Hong Kong, which consists of one hundred and ninety-four freshmen from the local universities. The relationship between freshmen's coping efforts and adjustment to university life in the Hong Kong context has been investigated, using the CSI as the measure of coping and the GHQ-12 as the screening instrument for mental health. The results indicate high internal consistency of the three CSI coping scales, implying that the CSI can be a valid instrument to assess the coping efforts of university students of Hong Kong. Moreover, the samples of freshmen are found to prefer positive coping strategies, and female students are more willing to seek social support than males in coping with stress.
\end{abstract}

\section{Keywords}

Stress, Coping Strategies, Avoidance, Problem Solving, Seek Social Support, University Freshmen, CSI, GHQ-12

\section{Introduction}

For the past few years Hong Kong has witnessed an increasing number of students committing suicide: 71 cases between 2013 and 2016 (Cheung, 2017; Erickson, 2017; Wong, 2017). Within the first six months of the academic year 2015-16, twenty-two students committed suicide in Hong Kong, and ten of them were university students (Cheung \& Chiu, 2016). According to the director of the University of Hong Kong's Centre for Suicide Research and Prevention, 
there are normally about two such suicides every year, and this drastic increase may be related to a change in the education system that makes students enter university a year earlier than before. The director pointed out that young adults were facing a turning point around the age of 18 , tended to encounter more difficulties, and might not be so well prepared for university life, so they needed more help and support from families and schools. A spokeswoman for The Chinese University of Hong Kong also reported that some incoming students had already shown symptoms of depression and anxiety even before the academic year started and that appropriate counselling services had been strengthened for those students.

Beyond question, entering university is a stressful experience for many students as it involves a multitude of new academic, personal and interpersonal challenges (Oppenheimer, 1984; Rickinson \& Rutherford, 1995; Shaver, Furman, \& Buhrmester, 1985, Tinto, 1993; Leong, Bonz, \& Zachar, 1997; Dyson \& Renk, 2006; Sasaki \& Yamasaki, 2007). In terms of academic challenges, the students are required to engage in more intellectually demanding work than previously undertaken (Guest, 2000; Hager, Sleet, Logan, \& Hooper, 2003; Lillis \& Turner, 2001), to adapt to new approaches to teaching and learning (Kantanis, 2000; Scanlon, Rowling, \& Weber, 2007; Wankowski, 1991), and to compete with peers for better scores (Krause, Hartley, James, \& McInnis, 2005). Regarding personal and interpersonal challenges, the students need to deal with issues relating to role change as well as establishing one's identity and personal values (Patiniotis \& Holdsworth, 2005; Scanlon, Rowling, \& Weber, 2007). In addition, students need to familiarize themselves with their new environment as well as to establish a new lifestyle, new routines and new social support networks (Beck, Taylor, \& Robbins, 2003; Rickinson \& Rutherford, 1995). Failing to meet these challenges and demands not only has a serious impact on students' academic achievement and health (both physical and mental), but also has become the most common reason for students quitting school (Gerdes \& Mallinckrodt, 1994). The incoming students thus have to draw upon coping strategies in dealing with their experience of stress when transitioning to university life. Consequently, to help students cope with the stress, preventive programs have been implemented by university administrations to provide appropriate counselling and outreach interventions to students (Fontana, Hyra, Godfrey, \& Cermak, 1999; Hirokawa, Yagi, \& Miyata, 2002; Nicholson, Belcastro, \& Duncan, 1989). In order to have effective preventive programs to help the freshmen, it is crucial to understand the process by which the students experience and cope with stress. Having the predictive power to identify students with potential adjustment problems can help counselors more efficiently serve a larger number of students.

In the psychological stress model of Lazarus \& Folkman (1984) coping is defined as the cognitive and behavioural efforts to manage psychological stress. More specifically, coping is a shifting process in which a person uses different strategies as the status of the person-environment relationship changes. When a person perceives an event as unchangeable or irreversible, he/she may employ an 
emotion-focused coping strategy to cope with the situation. On the other hand, a problem-focused coping strategy may be adopted if the person finds the stressful situation as manageable. For instance, a student uses confrontive coping before an examination, i.e. reviewing the lessons to prepare for the examination, whereas the same student uses distancing to cope with the frustration due to poor grades after the examination results are released. Besides, the avoidant types of coping strategies are commonly observed, too. These strategies may include wishful thinking, self-distraction, denial, or behavioural disengagement, and have negative impact on the individuals, especially if sustained over a long period of time (McNamara, 2000). Accordingly, how the freshmen adopt the coping strategies plays a significant role in their adjustment to university life. In fact, the adaptive ability among freshmen depends a lot upon their coping effort as well as the coping strategies used to deal with the challenges and demands encountered when entering university.

In order to assess coping effort systematically, Folkman \& Lazarus (1988) developed the Ways of Coping Questionnaire (WCQ) which measured individuals' coping effort through eight different types of coping strategies used, namely confrontive coping, distancing, self-controlling, seeking social support, accepting responsibility, escape-avoidance, planful problem-solving, and positive reappraisal. Halamandaris \& Power (1999) found that the subscales such as self-controlling, seeking social support, and accepting responsibility were significantly and positively correlated with university adjustment among students, while negative relationship was found in escape-avoidance. Distancing is found to correlate with students' academic performance, too. Moreover, as demonstrated by a number of studies (e.g. Aspinwall \& Taylor, 1992; Brissette, Scheier, \& Carver, 2002; Leong, Bonz, \& Zachar, 1997; Quinn, 1997; Rich \& Scovel, 1987; Sarason \& Sarason, 1999), active coping is found to have positive and direct effect on university adjustment whereas the stress related to ineffective coping may induce the development of various psychological symptoms in individuals, e.g. depression, feelings of hopelessness and sadness, etc. In particular, escape-avoidance coping is related to higher levels of psychological depression, while both positive reappraisal and planful problem solving are marginally related to higher levels of psychological well-being (Park \& Adler, 2003; Dyson \& Renk, 2006). Besides adjustment, positive and significant relationships between coping and students' grade point average have been observed as well. Hence, coping is an important psychological preditor of students' adjustment and academic achievement in university. Furthermore, one of the more consistent findings regarding gender and adjustment is that females tend to have poorer emotional adjustment during the transition than males (Alfeld-Liro \& Sigelman, 1998; Arthur \& Hiebert, 1996; Fisher \& Hood, 1988; Sinclair, Barkham, Evans, Connell, \& Audin, 2005; Vivona, 2000). Indeed, it has been observed that women are more likely to use emotion-focused coping strategies whereas men prefer problem-focused strategies. On the other hand, there is some evidence to suggest that females have more positive social adjustment than males because women 
are more willing to seek social support and are better socially integrated (Baker \& Siryk, 1989; Leong, Bonz, \& Zachar, 1997; Halamandaris \& Power, 1999).

All in all, the aforementioned empirical findings clearly point out that a poor adjustment to university life can lead to serious problems in the freshmen's subsequent mental health and academic performance. However, most of these studies are conducted in universities abroad and the students are very different culturally from those in local (Hong Kong) universities. We thus believe that it is timely to conduct an investigation of the relationship between coping efforts and adjustment to university in the Hong Kong context. The empirical findings should facilitate a better understanding of the coping processes involved and help shed light upon how the students' experience may be improved. As a result, more effective preventive programs can be designed and implemented to help the freshmen achieve a successful and smooth transition to university life.

Given the importance of coping and its implication to students' adjustment in university, the present study aims at examining the relationship between students' coping efforts and adjustment to university life in the local universities. To assess students' coping efforts, we adopt the Coping Strategy Indicator (CSI) developed by Amirkhan (1990) as the measure of coping, while we employ the 12-item General Health Questionnaire (GHQ-12) designed by Goldberg \& Williams (1992) for the purpose of detecting individuals with a diagnosable mental disorder. Equipped with these two instruments, the present study has the following specific objectives:

1) To validate the CSI with GHQ-12 as a criterion because the CSI has never been studied with Chinese samples;

2) To identify the coping preference among the freshmen; and

3) To test the hypothesis that females tend more likely to cope with stress via seeking social support than males.

\section{Method}

\subsection{Participants}

A total of 194 freshmen from the local universities of Hong Kong were recruited to participate in this study by convenience sampling and snowball sampling. However, 10 participants who were 23 years old or above ( 7 at the age of 23 to 28, and 3 between 35 and 50) were omitted in our analysis because they were considered as mature students and their coping efforts might differ significantly from the general freshmen population. Thus, the sample used in our analysis consists of 184 participants (age 18 to $22, \mathrm{M}=18.71, \mathrm{SD}=0.85$ ) only, of which 99 are women $(53.8 \%)$ and 85 are men $(46.2 \%)$.

\subsection{Measures}

Two instruments were administered to collect the research data. The first instrument is the Coping Strategy Indicator (CSI) developed by Amirkhan (1990) and the second one is the 12-item General Health Questionnaire (GHQ-12) designed by Goldberg \& Williams (1992). As the CSI has never been validated with 
Chinese samples, validity and reliability tests of the scales are thus conducted.

The CSI is a 33-item, 3-point self-report rating scale designed to assess three basic orthogonal modes of coping, namely problem solving, seeking social support, and avoidance. Participants select a stressful important event from their lives (for example, Unable to meet assessment deadline), which must have occurred within the past six months, and briefly describe it. Then participants, keeping that event in mind, respond to 33 questions (for example, Weighed up your options carefully, Daydreamed about better times) which are all scored in the same direction with "Not at all $=1$ ", “A little $=2$ ", and "A lot $=3$ ". Higher scores for a strategy indicate greater use of the strategy. These responses will indicate whether participants cope by problem solving, seeking social support, or avoiding the event. The CSI has been used to assess coping strategies for a wide variety of populations in various contexts (Spangenberg \& Orpen-Lyall, 2000; Desmond, Shevlin, \& MacLachlan, 2006; Jeglic et al., 2007; Simmons \& Hay, 2010; Luyckx et al., 2012; Li, 2014; Kim \& Han, 2015).

The GHQ-12 is the most extensively used, self-administered screening instrument for common mental disorders, in addition to being a more general measure of psychiatric well-being. Its brevity makes it attractive for use in busy clinical settings, and it is an effective measure of mental health. Its psychometric properties have been studied in various countries and with various types of population (Hankins, 2008; del Pilar Sánchez-López \& Dresch, 2008; Zulkefly \& Baharudin, 2010; Bakhla et al., 2013; Kim et al., 2013; Liang, Wang, \& Yin, 2016). The scoring scheme for each of the 12 questions (for example, Have you recently been thinking of yourself as a worthless person) is as follows: "Often = 3", "Sometimes $=2$ ", "Seldom $=1$ ", and "Never $=0$ ", with higher total scores being associated with more mental health symptoms. Since the GHQ-12 is an established mental health measuring instrument with reliability and validity studies on Chinese samples, no additional validity and reliability test is needed for our study.

\subsection{Procedures}

A questionnaire comprising both the 33 items of CSI and the 12 items of GHQ-12 was designed. Freshmen participants were recruited for completion of this questionnaire study. All the required briefing and de-briefing information were provided with the questionnaire. A webpage was created so that the study could be conducted online, too. Since the participants were over the age of 18 , no parental or guardian consent was needed.

\section{Results}

\subsection{Validating the CSI with GHQ-12 as a Criterion}

The first objective of this study is to validate the CSI with GHQ-12 as a criterion for a sample of Chinese university students. Each of the three CSI coping scales is summed over 11 selected items and then analyzed by the reliability tests. The corresponding Cronbach's alpha values and Spearman-Brown coefficients (unequal length) are given in Table 1: 
Obviously, these Cronbach's alpha values and Spearman-Brown coefficients are strong, suggesting high internal consistency of the three scales. In addition, the corrected item-total correlations are computed and the numerical results can be summarized as follows:

1) For the "Avoidance" scale, while items 6, 13, 26 and 30 have corrected item-total correlation values ranging between 0.2 and 0.4 , the rest have values higher than 0.4 , except Item 10 which has a very small value of 0.063 for the corrected correlation. ${ }^{1}$

2) For both "Problem Solving" scale and "Seek Social Support" scale, all items have corrected item-total correlation values higher than 0.4 .

Before performing the correlation analysis, normality checks for the three CSI scales and GHQ-12 are conducted. The following descriptive statistics data are obtained:

1) GHQ-12: Skewness $=-0.274$ with $\mathrm{SE}=0.190 ;$ Kurtosis $=0.288$ with $\mathrm{SE}=$ 0.378 ;

2) "Avoidance": Skewness $=0.327$ with $\mathrm{SE}=0.190$; Kurtosis $=0.373$ with $\mathrm{SE}=$ 0.378 ;

3) "Problem Solving": Skewness $=-0.058$ with $\mathrm{SE}=0.190 ;$ Kurtosis $=-0.376$ with $\mathrm{SE}=0.378$;

4) "Seek Social Support": Skewness $=-0.112$ with $\mathrm{SE}=0.190 ;$ Kurtosis $=0.088$ with $\mathrm{SE}=0.378$.

It is clear that the skewness and Kurtosis data all seem to imply normal distributions. Other results like the Q-Q plots, box plots and histograms with normal distribution curves are scrutinized such that the parametric assumptions of CSI scales and GHQ-12 can be checked.

Scatter plots with lines of best fit are also examined to check for the linear assumptions involving Pearson correlations. Results of the scatter plots indicate that all the correlations are linear. As such, the Pearson correlation coefficients among GHQ-12 and the three CSI scales are computed via SPSS bivariate correlation functions as follows:

1) Pearson correlation between a) GHQ-12 and "Avoidance" is ( $\mathrm{r}=0.319, \mathrm{p}=$ $0.000, \mathrm{n}=173,2$-tailed), b) GHQ-12 and "Problem Solving" is ( $\mathrm{r}=-0.288, \mathrm{p}=$ $0.000, \mathrm{n}=170,2$-tailed), and c) GHQ-12 and "Seek Social Support" is ( $\mathrm{r}=$ $-0.016, \mathrm{p}=0.834, \mathrm{n}=177,2$-tailed). Thus, the GHQ-12 is a valid criterion for both "Avoidance" and "Problem Solving".

2) Pearson correlation between a) "Avoidance" and "Problem Solving" is

Table 1. The Cronbach's alpha values and spearman-brown coefficients.

\begin{tabular}{ccc}
\hline & Cronbach's alpha & Spearman-Brown coefficient \\
\hline Avoidance & 0.730 & 0.753 \\
Problem solving & 0.861 & 0.876 \\
Seek social support & 0.898 & 0.897 \\
\hline
\end{tabular}

${ }^{1}$ The author includes this item because removing it only results in slight adjustment of Cronbach's alpha. 
( $\mathrm{r}=0.167, \mathrm{p}=0.030, \mathrm{n}=170,2$-tailed), $\mathrm{b})$ "Avoidance" and "Seek Social Support" is ( $\mathrm{r}=0.374, \mathrm{p}=0.000, \mathrm{n}=176,2$-tailed), and c) "Problem Solving" and "Seek Social Support" is ( $\mathrm{r}=0.351, \mathrm{p}=0.000, \mathrm{n}=173,2$-tailed). Accordingly, all CSI scales correlate with each other, and this casts doubt on the claim that the three scales are orthogonal to each other.

Furthermore, linear regression is applied to determine the linear relations between the GHQ-12 and each of the three CSI coping strategies (i.e. the predictors). The standardized coefficients are a) (beta $=0.392, \mathrm{p}=0.000$ ) for "Avoidance", b) (beta $=-0.338, \mathrm{p}=0.000)$ for "Problem Solving", and c) (beta $=$ $-0.44, \mathrm{p}=0.574)$ for "Seek Social Support". Hence, both "Avoidance" and "Problem Solving" are good predictors of the GHQ-12, but "Seek Social Support" is not. This is consistent with the results of correlation analysis.

\subsection{Coping Preference among Students}

To address the second objective of this study, students' effort in coping with stressful event is analyzed using descriptive statistic. Findings indicate that among the three basic modes of CSI coping, the coping strategy most preferred or used by students when encountered with stressful situation is "Problem Solving" (Mean $=24.15, \mathrm{SD}=4.50,95 \%$ CI $[23.46,24.85])$, followed by "Seek Social Support" (Mean $=22.44, \mathrm{SD}=5.19,95 \%$ CI $[21.63,23.24])$ and "Avoidance" $($ Mean $=20.46, \mathrm{SD}=3.87,95 \%$ CI $[19.86,21.06])$.

Besides, in this study the total GHQ-12 score has a mean of 16.76 (SD $=4.57$, $95 \%$ CI $[16.05,17.47])$. In spite of large variations in the best threshold to adopt (Goldberg et al., 1997; Goldberg, Oldehinkel, \& Ormel, 1998), it is essential to establish a criterion before the GHQ-12 can serve as a screening tool for mental health. A rough indicator for the best cut-off point could be the mean total GHQ-12 score for a population of participants; that is, in this study the cut-off point 17/18 could be utilized to determine the participants' level of psychological well-being (Goldberg, Oldehinkel, \& Ormel, 1998). Using the cut-off point of 18, it is found that $45.81 \%$ of the students scored 18 and above while $54.19 \%$ obtained scores below 18 .

\subsection{Hypothesis Testing}

To test the hypothesis that females tend more likely to cope with stress via seeking social support than males, we need to compare the "Seek Social Support" scores of females with those of males via the independent sample t-test: Female (Mean $=23.32, \mathrm{SD}=4.97)$ and Male (Mean $=21.66, \mathrm{SD}=4.95)$. Results of the $\mathrm{t}$-test are: $\mathrm{t}(180)=-2.249, \mathrm{p}=0.026$, and $95 \%$ CI $[-3.12,-0.20]$; obviously the differences are statistically significant. Hence, the results show that females are more willing to seek social support than males in coping with stress.

\section{Discussion}

This study has explored validating the CSI with GHQ-12 as a criterion for a sample of Chinese university students in Hong Kong, and the results indicate 
high internal consistency of the three CSI scales. Since the CSI has never been studied with Chinese samples, this study represents the very first attempt. The empirical findings suggest that the CSI could be a valid instrument to assess the coping efforts of university students of Hong Kong.

The correlation analyses and linear regressions have demonstrated that the coping strategies "Avoidance" and "Problem Solving" not only have significant correlations with GHQ-12 but also serve as its good predictors. This in turn has provided important evidence that coping efforts and strategies (except "Seek Social Support") are directly related to freshmen's adjustment to university life. The positive relationship found between GHQ-12 and "Avoidance" (or equivalently, the negative relationship found between university adjustment and "Avoidance") is also supported by previous studies conducted by Aspinwall \& Taylor (1992), Halamandaris \& Power (1999), Park \& Adler (2003), and Dyson \& Renk (2006), which reported the negative impact of "Avoidance" coping strategy on university adjustment, especially the mental health of students. Moreover, the negative relationship found between GHQ-12 and "Problem Solving" suggests that positive coping strategies can lead to higher levels of mental health (Park \& Adler, 2003).

In addition, the findings of this study indicate that the sample of Hong Kong Chinese university students seem to prefer positive coping strategies (namely, "Problem Solving" and "Seek Social Support"), especially "Problem Solving". One possible explanation may be that since convenient sampling is used in recruiting participants and a fairly large portion of the participants come from science-related disciplines which emphasize teaching problem-solving skills to the students, the randomness of the sample is questionable and bias is inevitable. Hence, a truly random sample is needed to avoid such bias. Furthermore, female students are found to use the coping strategy "Seek Social Support" to a greater extent than their male counterparts. This is consistent with previous studies (Baker \& Siryk, 1989; Leong, Bonz, \& Zachar, 1997; Halamandaris \& Power, 1999) and may be a reflection of the general tendency among females to have a higher level of the need for affiliation and to be more concerned with achieving acceptance and good social interaction than males (Gerdes, 1988).

Furthermore, the descriptive analysis reveals that although more than half (54.19\%) of the participants scored below the cut-off point of 18 , a substantial proportion $(45.81 \%)$ obtained scores above this cut-off point. This seems to suggest that the students are psychologically healthy in general but a considerable proportion of them has been identified to have the potential to develop psychological problems. The pressure faced by Hong Kong students to excel in higher education in order to gain social mobility might have put the psychological well-being of a good number of them at risk. Perhaps the recent drastic increase in the number of students committing suicide has given us a warning signal.

In summary, this study has provided some evidence that students' choice of coping strategies has a critical impact on their adjustment to university life. 
Frequent use of positive coping strategies to deal with the demands and challenges encountered helps students achieve a smooth transition to university more easily. On the contrary, the "Avoidance" strategy may decrease students' level of adjustment and thus more adjustment problems are anticipated subsequently. Hence, it is important that the relevant administrations, such as policy makers, university administrators, counselors, academic advisors, etc., can provide suitable guidance for the students to identify various coping strategies to overcome stressful encounters during the transition to university. In particular, counselors and academic advisors should equip themselves with the knowledge of coping so that they are capable of advising students how to effectively use coping strategies to reduce stress in confronting adjustment problems. Coping training sessions for university freshmen can also be included in the orientation program of each academic year in order to familiarize the students with different coping strategies using hypothetical and real life situations, as suggested by Folkman et al. (1991). Above all, being optimistic and having positive values, with a supportive learning environment, are crucial in motivating students' learning and reducing their stress.

There are two major limitations in this study. First, the sample in this study was obtained by convenience sampling and might not represent the whole population (Hong Kong university freshmen). Second, data collection was based upon participants' self-report, so their subjective perspectives could not be avoided.

\section{Acknowledgements}

The author would like to thank Dr. Herbert Chiu for his useful comments and suggestions. The collection of data was conducted by the first cohort of students of the M. Sc. Psychology (Hong Kong) Program of Sheffield-Hallam University.

\section{References}

Alfeld-Liro, C., \& Sigelman, C. K. (1998). Sex Differences in Self-Concept and Symptoms of Depression during the Transition to College. Journal of Youth and Adolescence, 27, 219-243. https://doi.org/10.1023/A:1021667813858

Amirkhan, J. H. (1990). A Factor Analytically Derived Measure of Coping: The Coping Strategy Indicator. Journal of Personality and Social Psychology, 59, 1066-1074. https://doi.org/10.1037/0022-3514.59.5.1066

Arthur, N., \& Hiebert, B. (1996). Coping with the Transition to Post-Secondary Education. Canadian Journal of Counselling, 30, 93-103.

Aspinwall, L. G., \& Taylor, S. E. (1992). Modeling Cognitive Adaptation: A Longitudinal Investigation of the Impact of Individual Differences and Coping on College Adjustment and Performance. Journal of Personality and Social Psychology, 63, 989-1003. https://doi.org/10.1037/0022-3514.63.6.989

Baker, R. W., \& Siryk, B. (1989). Student Adaptation to College Questionnaire Manual. Los Angeles: Western Psychological Services.

Bakhla, A. K., Verma, V., Hembram, M., Praharaj, S. K., \& Sinha, V. K. (2013). Internal Consistency and Factor Structure of 12-Item General Health Questionnaire in Visually Impaired Students. Industrial Psychiatry Journal, 22, 109-113. 
https://doi.org/10.4103/0972-6748.132918

Beck, R., Taylor, C., \& Robbins, M. (2003). Missing Home: Sociology and Autonomy and Their Relationship to Psychological Distress and Homesickness in College Freshmen. Anxiety, Stress and Coping, 16, 155-166. https://doi.org/10.1080/10615806.2003.10382970

Brissette, I., Scheier, M. F., \& Carver, C. S. (2002). The Role of Optimism in Social Network Development, Coping and Psychological Adjustment during a Life Transition. Journal of Personality and Social Psychology, 82, 102-111. https://doi.org/10.1037/0022-3514.82.1.102

Cheung, E. (2017). After 71 Student Suicides Since 2013, Education Chief Told Hong Kong Schools Are Like a "Prison". South China Morning Post, January 7.

Cheung, E., \& Chiu, P. (2016). Twenty-Two Young People Have Taken Their Lives so far This Academic Year. Is the City's Pressure-Cooker Education System Solely to BlameOr Is It More Complex? South China Morning Post, March 12.

Del Pilar Sánchez-López, M., \& Dresch, V. (2008). The 12-Item General Health Questionnaire (GHQ-12): Reliability, External Validity and Factor Structure in the Spanish Population. Psicothema, 20, 839-843.

Desmond, D. M., Shevlin, M., \& MacLachlan, M. (2006). Dimensional Analysis of the Coping Strategy Indicator in a Sample of Elderly Veterans with Acquired Limb Amputations. Personality and Individual Differences, 40, 249-259. https://doi.org/10.1016/j.paid.2005.04.015

Dyson, R., \& Renk, K. (2006). Freshmen Adaptation to University Life: Depressive Symptoms, Stress and Coping. Journal of Clinical Psychology, 62, 1231-1244. https://doi.org/10.1002/jclp.20295

Erickson, A. (2017). What's behind the Student Suicides Sweeping Hong Kong? The Washington Post, February 25.

Fisher, S., \& Hood, B. (1988). Vulnerability Factors in the Transition to University: Self-Reported Mobility History and Sex Differences as Factors in Psychological Disturbance. British Journal of Psychology, 79, 309-320.

https://doi.org/10.1111/j.2044-8295.1988.tb02290.x

Folkman, S., \& Lazarus, R. S. (1988). Manual for the Ways of Coping Questionnaire. Palo Alto, CA: Consulting Psychologists Press.

Folkman, S., Chesney, M., Mckusick, L., Ironson, G., Johnson, D. S., \& Coates, T. J. (1991). Translating Coping Theory into an Intervention. In D. J. Eckenrode (Ed.), The Social Context of Coping (pp. 239-260). New York: Plenum Press. https://doi.org/10.1007/978-1-4899-3740-7_11

Fontana, A. M., Hyra, D., Godfrey, L., \& Cermak, L. (1999). Impact of a Peer-Led Stress Inoculation Training Intervention on State Anxiety and Heart Rate in College Students. Journal of Applied Biobehavioural Research, 4, 45-63. https://doi.org/10.1111/j.1751-9861.1999.tb00054.x

Gerdes, H., \& Mallinckrodt, B. (1994). Emotional, Social, and Academic Adjustment of College Students: A Longitudinal Study of Retention. Journal of Counseling \& Development, 72, 281-288. https://doi.org/10.1002/j.1556-6676.1994.tb00935.x

Gerdes, L. C. (1988). The Developing Adult (2nd ed.). Durban: Butterworths.

Goldberg, D. P., \& Williams, J. E. (1992). A User's Guide to the General Health Questionnaire. London: NFER-Nelson.

Goldberg, D. P., Gater, R., Sartorius, N., Ustun, T. B., Piccinelli, M., Gureje, O., \& Rutter, C. (1997). The Validity of Two Versions of the GHQ in the WHO Study of Mental Illness in General Health Care. Psychological Medicine, 27, 191-197. 
Goldberg, D. P., Oldehinkel, T., \& Ormel, J. (1998). Why GHQ Threshold Varies From One Place to Another. Psychological Medicine, 28, 915-921. https://doi.org/10.1017/S0033291798006874

Guest, K. (2000). Introducing Critical Thinking to "Non-Standard" Entry Students. The Use of a Catalyst to Spark Debate. Teaching in Higher Education, 5, 289-299. https://doi.org/10.1080/713699139

Hager, P., Sleet, R., Logan, P., \& Hooper, M. (2003). Teaching Critical Thinking in Undergraduate Science Courses. Science and Education, 12, 303-313. https://doi.org/10.1023/A:1024043708461

Halamandaris, K. F., \& Power, K. G. (1999). Individual Differences, Social Support and Coping with the Examination Stress: A Study of the Psychosocial and Academic Adjustment of First Year Home Students. Personality and Individual Differences, 26, 665685. https://doi.org/10.1016/S0191-8869(98)00172-X

Hankins, M. (2008). The Reliability of the Twelve-Item General Health Questionnaire (GHQ-12) under Realistic Assumptions.BMC Public Health, 8, 355, 7 p. https://doi.org/10.1186/1471-2458-8-355

Hirokawa, K., Yagi, A., \& Miyata, Y. (2002). An Examination of the Effects of Stress Management Training for Japanese College Students of Social Work. International Journal of Stress Management, 9, 113-123. https://doi.org/10.1023/A:1014906820573

Jeglic, E. L., Pepper, C. M., Vanderhoff, H. A., \& Ryabchenko, K. A. (2007). An Analysis of Suicidal Ideation in a College Sample. Archives of Suicide Research, 11, 41-56. https://doi.org/10.1080/13811110600897176

Kantanis, T. (2000). The Role of Social Transition in Students' Adjustment to the First-Year of University. Journal of Institutional Research, 9, 100-110.

Kim, M. R., \& Han, S. J. (2015). A Study of Emotional Intelligence and Coping Strategies in Baccalaureate Nursing Students. International Journal of Bio-Science and BioTechnology, 7, 275-282. https://doi.org/10.14257/ijbsbt.2015.7.3.29

Kim, Y. J., Cho, M. J., Park, S., Hong, J. P., Sohn, J. H., Bae, J.N., Jeon, H. J., Chang, S. M., Lee, H. W., \& Park, J. I. (2013). The 12-Item General Health Questionnaire as an Effective Mental Health Screening Tool for General Korean Adult Population. Psychiatry Investigation, 10, 352-358. https://doi.org/10.4306/pi.2013.10.4.352

Krause, K., Hartley, R., James, R., \& McInnis, C. (2005). The First Year Experience in Australian Universities: Findings from a Decade of National Studies. Canberra: Australian Department of Education, Science and Training.

Lazarus, R. S., \& Folkman, S. (1984). Stress, Appraisal and Coping. New York: Springer.

Leong, F. T. L., Bonz, M. H., \& Zachar, P. (1997). Coping Styles as Predictors of College Adjustment among Freshmen. Counselling Psychology Quarterly, 10, 211-220. https://doi.org/10.1080/09515079708254173

Li, M. H. (2014). Effect of Stress, Perception-Related Traits, and Motivation on Different Coping Strategies. International Journal of Humanities and Social Science, 4, 7-16.

Liang, Y., Wang, L., \& Yin, X. (2016). The Factor Structure of the 12-Item General Health Questionnaire (GHQ-12) in Young Chinese civil Servants. Health and Quality of Life Outcomes, 14, 136, 9 p. https://doi.org/10.1186/s12955-016-0539-y

Lillis, T., \& Turner, J. (2001). Student Writing in Higher Education: Contemporary Confusion, Traditional Concerns. Teaching in Higher Education, 6, 57-68. https://doi.org/10.1080/13562510020029608

Luyckx, K., Klimstra, T. A., Duriez, B., Schwartz, S. J., \& Vanhalst, J. (2012). Identity Processes and Coping Strategies in College Students: Short-Term Longitudinal Dy- 
namics and the Role of Personality. Journal of Youth Adolescence, 41, 1226-1239. https://doi.org/10.1007/s10964-012-9753-Z

McNamara, S. (2000). Stress in Young People: What's New and What Can We Do? New York: Continuum.

Nicholson, T., Belcastro, P. A., \& Duncan, D. F. (1989). An Evaluation of a University Stress Management Program. College Student Journal, 23, 76-81.

Oppenheimer, B. T. (1984). Short-Term Small Group Intervention for College Freshmen. Journal of Counseling Psychology, 31, 45-53. https://doi.org/10.1037/0022-0167.31.1.45

Park, C. L., \& Adler, N. E. (2003). Coping Style as a Predictor of Health and Well-Being across the First Year of Medical School. Health Psychology, 22, 627-631. https://doi.org/10.1037/0278-6133.22.6.627

Patiniotis, J., \& Holdsworth, C. (2005). 'Seize That Chance!' Leaving Home and Transitions to Higher Education. Journal of Youth Studies, 8, 81-95.

https://doi.org/10.1080/13676260500063710

Quinn, B. P. (1997). The Depression Sourcebook. Los Angeles: Lowell House.

Rich, A. R., \& Scovel, M. (1987). Causes of Depression in College Students: A CrossLagged Panel Correlation Analysis. Psychological Reports, 60, 27-30. https://doi.org/10.2466/pr0.1987.60.1.27

Rickinson, B., \& Rutherford, D. (1995). Increasing Undergraduate Student Retention Rates. British Journal of Guidance and Counselling, 23, 161-172. https://doi.org/10.1080/03069889508253002

Sarason, I. G., \& Sarason, B. R. (1999). Abnormal Psychology: The Problem of Maladaptive Behaviour (9th ed.). Upper Saddle River, NJ: Prentice Hall.

Sasaki, M., \& Yamasaki, K. (2007). Stress Coping and the Adjustment Process among University Freshmen. Counselling Psychology Quarterly, 20, 51-67. https://doi.org/10.1080/09515070701219943

Scanlon, L., Rowling, L., \& Weber, Z. (2007). "You Don't Have Like an Identity...You Are Just Lost in a Crowd": Forming a Student Identity in the First Year Transition to University. Journal of Youth Studies, 10, 223-242. https://doi.org/10.1080/13676260600983684

Shaver, P. R., Furman, W., \& Buhrmester, D. (1985). Transition to College: Network Changes, Social Skills, and Loneliness. In S. Duck \& D. Perlman (Eds.), Understanding Personal Relationships: An Interdisciplinary Approach (pp. 193-219). Thousand Oaks, CA: Sage.

Simmons, N., \& Hay, I. (2010). Early Adolescents' Friendship Patterns in Middle School: Social-Emotional and Academic Implications. The Australian Educational and Developmental Psychologist, 27, 59-69. https://doi.org/10.1375/aedp.27.2.59

Sinclair, A., Barkham, M., Evans, C., Connell, J., \& Audin, K. (2005). Rationale and Development of a General Population Well-Being Measure: Psychometric Status of the GP-CORE in A Student Sample. British Journal of Guidance and Counselling, 33, 153 173. https://doi.org/10.1080/03069880500132581

Spangenberg, J. J., \& Orpen-Lyall, M. R. (2000). Stress and Coping Strategies in a Sample of South African Managers Involved in Post-Graduate Managerial Studies. Journal of Industrial Psychology, 26, 6-10. https://doi.org/10.4102/sajip.v26i1.692

Tinto, V. (1993). Leaving College: Rethinking the Causes and Cures of Student Attrition (2nd ed.). Chicago: University of Chicago Press.

Vivona, J. M. (2000). Parental Attachment Styles of Late Adolescents: Qualities of Attachment Relationships and Consequences for Adjustment. Journal of Counseling Psychology, 47, 316-329. https://doi.org/10.1037/0022-0167.47.3.316 
Wankowski, J. (1991). Increasing Students' Power for Self-Teaching. In K. Raaheim, J. Wankowski, \& J. Radford (Eds.), Helping Students Learn. Buckingham: SRHE and OUP.

Wong, C. (2017). Hong Kong's Wave of Student Suicides. The Diplomat, March 1.

Zulkefly, N. S., \& Baharudin, R. (2010). Using the 12-Item General Health Questionnaire (GHQ-12) to Assess the Psychological Health of Malaysian College Students. Global Journal of Health Science, 2, 71-80. https://doi.org/10.5539/gjhs.v2n1p73

Submit or recommend next manuscript to SCIRP and we will provide best service for you:

Accepting pre-submission inquiries through Email, Facebook, LinkedIn, Twitter, etc. A wide selection of journals (inclusive of 9 subjects, more than 200 journals)

Providing 24-hour high-quality service

User-friendly online submission system

Fair and swift peer-review system

Efficient typesetting and proofreading procedure

Display of the result of downloads and visits, as well as the number of cited articles Maximum dissemination of your research work

Submit your manuscript at: http://papersubmission.scirp.org/

Or contact psych@scirp.org 